HYPERTHERMIA IN GONOCOCCAL AND NON-SPECIFIC URETHRITIS

\title{
HYPERTHERMIA IN THE TREATMENT OF RESISTANT GONOCOCCAL AND NON-SPECIFIC URETHRITIS*
}

\author{
By A. J. KING, Lt.-col. R.A.M.C., D. I. WILlIAMS, Maj. R.A.M.C., and \\ C. S. NICOL, Maj. R.A.M.C.
}

The subject of the treatment of gonorrhoea by high fever mechanically produced is not a new one to the members of this Society. The extensive literature which this subject has acquired during the past ten years, papers personally delivered by Dr. Walter Simpson and Professor Bessemans and more recent articles in the British Journal of Venereal Diseases, by Rose, Kendell and Simpson (1941), have served to stimulate and maintain interest. Nevertheless, considering the excellence of reported results there has been remarkably little practical work done in this subject in Great Britain. The reasons for this are perhaps to be found first in the high hopes that were entertained for the sulphonamide drugs (which like most valuable remedies have been found to have their limitations); secondly in the fact that the application of this treatment is not easy and that faulty technique means danger to the patient; and thirdly in an inborn suspicion of machineproduced remedies.

Our own methods have been built up arduously and in the face of many difficulties. By the best standards they still have imperfections, the reasons for which will be discussed. Up to the time of writing our total experience of this treatment, excluding the experience gained by one of us in civil life, has been gained in 758 treatments administered to 550 patients in the course of approximately twenty months. This total includes a number of cases of arthritis and a few of syphilis.

\section{Previous reports on fever therapy}

No attempt is made to summarize the very extensive literature of fever therapy in general but it is important briefly to refer to that development of this treatment first devised by Simpson, Kendell and Rose in which sessions of fever are immediately preceded by the administration of sulphonamide compounds.

Series of cases treated according to various schemes in which fever and sulphonamides were combined have been described by Simpson, Kendell and Rose (1941) by Belt and Folkenberg (1940) and by Ferguson, Buchholtz, Gersten and Cutler (1942) in the United States of America ; and by Batchelor, Thomson and Huggan (1942) in Great Britain who reported on their results in six cases.

\section{Apparatus}

Apparatus of the most up-to-date type is, unfortunately, almost unobtainable at the present time, but it may be postulated that the more efficient the cabinet the lower the temperature of the cabinet air and the less body chloride and fluid the patient will lose by sweating. These are factors which make for the avoidance of the complications of treatment and for the greater safety and comfort of the patient.

Temperature recording apparatus is fragile and easily damaged by restless or delirious patients. Such is the shortage of skilled workers that repairs are much delayed and we have at most times been without one of these instruments. In these circumstances rectal temperatures have to be taken by means of clinical thermometers inserted every ten to fifteen minutes. This involves interference with the patient, frequent opening of cabinet doors and the absence of a constant record of temperature. Such factors militate further against the safety and efficiency of treatments.

All our treatments have been given in apparatus of the type known as the Kettering Hypertherm, the mechanism of which is too well known to require more than a brief description. The older machine consists of a Masonite cabinet in

* A paper read to the Medical Society for the Study of Venereal Diseases, 24th July, 1943. 


\section{THE BRITISH JOURNAL OF VENEREAL DISEASES}

which the patient lies on a retractable carriage fitted with a comfortable air mattress. When the carriage is placed within the cabinet a flap with a neck opening is lowered at the head end and the patient lies within the cabinet with his head projecting. Insulation is maintained by draping towels round the neck. Heat is applied from a unit in the roof at the foot of the cabinet consisting of two heaters of different voltage in a waterbath and also a dry heater. Only the moist heaters are used while the patient is in the cabinet and the moist hot air is driven forwards by a fan, then it passes down through the holes in a false roof over the patient's body and back through the heating unit. With the cabinet closed, humidity of 80 to 95 per cent can be maintained. The dry heater is only used for heating up the cabinet and for drying it after use. On either side of the patient is a large sliding door which can be opened for ordinary nursing purposes. During the period of induction of fever a high cabinet temperature is required-as much as $140^{\circ} \mathrm{F}$.and it is necessary to cover the patient's body with blankets. When the required body temperature is reached, the cabinet temperature can usually be maintained at from $110^{\circ}-112^{\circ} \mathrm{F}$. and the blankets can be removed. At the head of the cabinet are two large fans which can direct air on to the patient's head.

The newer apparatus is modified in certain important respects. It is an all-metal cabinet, the hood of which can be lifted easily and quickly, and the retractable carriage has been dispensed with. The heating unit, consisting of a large waterbath with plate heater, a dry heater and a fan, is situated under the bed on which the patient lies, and hot air comes up at the sides and the foot end of the patient's mattress and so is not projected straight on to his body. The temperature of the cabinet is controlled by a thermostat which is in turn regulated by an adjustable switch. It is usually possible to induce fever with a cabinet temperature of from $116^{\circ}-120^{\circ} \mathrm{F}$. and to maintain fever with the cabinet air registering $110^{\circ} \mathrm{F}$. or lower. The patient's body does not need to be covered and the risk of burns is practically eliminated. This type of cabinet is a big improvement on the older model, but it has the disadvantage that if the cabinet temperature falls below the level indicated by the control switch, the thermostat makes contact and the heat is automatically switched on both in the waterbath and in the coil of the dry heater. The sudden blast of heat is apt to cause the patient considerable discomfort and distress and with this form of control it is seldom possible to maintain the patient's temperature at $106^{\circ} \mathrm{F}$. without a cabinet temperature of $110^{\circ} \mathrm{F}$. During a recent visit to the Chicago Intensive Treatment Centre one of us was shown an important modification of this apparatus by which more sensitive control was possible. The dry heater was removed and the thermostat disconnected. In its place a rheostat with fifteen to twenty button contacts was introduced into the circuit, enabling the cabinet temperature to be adjusted according to the trend of the patient's temperature. By this means, it was usually possible to maintain the patient's temperature at $106^{\circ} \mathrm{F}$. with a cabinet temperature the same as that of the patient or lower. In consequence the patient was very much more comfortable and perspired less.

The patient's temperature is measured by means of a resistance thermometer with a terminal inserted in the rectum and connected by leads with the circuit of a graduated galvanometer indicator. This gives an exact measurement of the patient's temperature at all times, provided that the indicator is accurately set at the beginning of treatment. The accuracy of this instrument has to be checked against standard clinical thermometers. Recent work at the Chicago Centre has pointed to an important source of possible errors in such readings. It was suspected that clinical thermometers, which gave accurate readings at and for a certain range above body temperature, were inaccurate for the high fever levels of $105^{\circ} \mathrm{F}$. and over. In order to investigate this point a constant temperature mercury bath was obtained. A good thermometer was standardized at the Bureau of Standards for the $100^{\circ}-110^{\circ} \mathrm{F}$. range, the Bureau providing the correct figures of adjustment for this standard thermometer in this temperature range. The mercury bath was then set at $105^{\circ} \mathrm{F}$. and checked by the standard thermometer. Twelve clinical thermometers in ordinary use were tested. None of these gave 


\section{HYPERTHERMIA IN GONOCOCCAL AND NON-SPECIFIC URETHRITIS}

an exact reading and the limits of error were plus 0.6 degrees and minus 0.6 degrees. By means of this constant temperature mercury bath the automatic indicating thermometers used at Chicago were set to record accurate temperatures before use each morning and all clinical thermometers, by which indicating thermometers were checked from time to time during the day, were similarly tested so that the degree of error was known. This is a most important method of ensuring safety by providing exact records of the patient's temperature at these potentially dangerous high fever levels.

\section{Standards of fitness for fever therapy}

In all our cases, a general physical examination by a physician preceded fever therapy. The standard of fitness required was that essential for a patient about to undergo a major surgical operation. In doubtful cases X-ray examination of the chest and renal function tests or blood count were made; the electrocardiograph was also used. Liver function tests were performed when indicated. The mental as well as the physical condition of the patient must be considered before treatment is undertaken. Patients must have sufficient resolution to face an arduous treatment, and those who lack self-control or are indifferent to the success of their treatment are unsuitable. Men with a bad army record do not usually make good patients.

\section{Technique of fever therapy}

When treatment was started in November, 1941 the following technique was employed.

Preliminary management.-The patient was given a full diet up to the evening preceding fever, when he was put to bed, given a soap-sud enema, and a sedative (veronal, $7 \frac{1}{2}$ grains). No breakfast was given on the morning of treatment. Sulphanilamide, 10 grammes in five divided doses, was given in the eighteen hours preceding fever.

Procedure in fever treatment.-At 7.30 a.m. the patient was weighed and readings were taken of his blood pressure, rectal temperature and pulse rate. The temperature and humidity of the cabinet were checked, and the patient was then placed in it. His temperature and pulse rate were recorded on a special chart at fifteenminute intervals and his blood pressure checked every hour during treatment. One fan was switched on when the rectal temperature was $101^{\circ} \mathrm{F}$. When the patient's temperature reached $106 \cdot 6^{\circ} \mathrm{F}$. the side door of the cabinet was opened, ice was rubbed on his chest and the blood pressure was estimated. This induction period usually occupied from forty-five to ninety minutes. The second fan was now switched on and ice applied to the patient's face and neck, and the cabinet temperature regulated so that the patient's temperature was maintained at the same level.

The patient was encouraged to drink 200 cubic centimetres of iced. 0.6 per cent sodium chloride solution every fifteen minutes during the maintenance of fever so that a minimum of three litres was taken during treatment. Intravenous solutions of 50 per cent glucose and 10 per cent glucose in normal saline were available for administration when indicated.

When the desired period of fever (usually eight hours) was completed, the cabinet was opened and the fans were played upon the patient's body. His blood pressure was estimated and an astringent solution dabbed on arms, body and legs. This was followed by a blanket bath and the patient was finally taken back to bed when his temperature had fallen to $101^{\circ} \mathrm{F}$.

After-care and treatment.- The patient was kept under observation till 6 a.m. the next morning, when he was returned to his ward. His temperature, pulse rate and blood pressure were recorded hourly by the nurse in charge. $\mathrm{He}^{-}$was allowed only small sips of water by mouth. On the following day if the patient was fit he was allowed to have an ordinary diet ; twenty-four hours later he was given permission to rise.

Since November, 1941, as a result of experience gained and investigations performed in this Department, as well as the adoption of improvements and 


\section{THE BRITISH JOURNAL OF VENEREAL DISEASES}

suggestions of workers in this subject in the United States of America, our technique has undergone many changes. The various modifications are summarized as follows.

\section{Modifications}

Preliminary management.-Although a limited number of patients were given sulphanilamide and sulphapyridine as premedication, the administration of sulphathiazole in 2-gramme doses at 8 p.m., 12 midnight and 4 a.m. has been a routine for some time. This drug was also given in a few cases in a single (7-gramme) dose and in another small number of cases in two doses of $3 \frac{1}{2}$ grammes each. Sulphadiazine has been given to a few patients in whom an idiosyncrasy for sulphathiazole had been previously observed.

It was considered at one time that certain complications which had occurred might be due to chloride deficiency, and sodium chloride tablets to the amount of 8 grammes daily were given in the two days preceding fever. Furthermore during a period of investigation, 1,000 cubic centimetres of normal saline solution was given intravenously immediately before fever therapy. These methods of chloride premedication have now been discontinued as there seems to be no clear evidence of their benefit. Glucose was also given to the amount of 200 grammes on each of the two days preceding fever, and 50 grammes were given on the morning of treatment. This practice has also been discontinued as its value appears to be doubtful. Recently sulphur-containing foods have been given to all patients before they undergo fever therapy. Two eggs, two ounces of cheese and four quarts of milk have been given in the two days preceding fever, while some patients have taken an additional 4 or 5 grammes of cysteine ester in 1-gramme doses. The use of sedatives before fever proved to be unnecessary and was discontinued.

Procedure in fever treatment.-Oxygen or oxygen and carbon dioxide mixture was administered for short periods only during treatment in some of the earlier cases either by means of a B.L.B. nasal mask or by nasal catheter, but continuous oxygen was later used as recommended by Simpson, Kendell and Rose. The advantages of this method were upheld by Wallace and Bushby during their investigations on a small series of our cases. An oro-nasal B.L.B. mask was found to be more suitable than the nasal type in most cases. The nasal catheter is a less effective method of administering oxygen but is preferred in most centres for the reason that it is much more comfortable for the patient.

Our present technique is to give during the induction period oxygen and carbon dioxide mixture ( 5 to 7 per cent), by a B.L.B. mask of the oro-nasal type. Oxygen or oxygen and carbon dioxide therapy is continued throughout the maintenance of fever, but the patient may be allowed short rests (five to ten minutes) from the mask during the later part of the treatment. A nasal catheter is substituted for the mask if the patient is unable to tolerate the latter. The flow of oxygen required for the B.L.B. mask is from eight to ten litres a minute and for the nasal catheter four to six litres a minute. When the catheter is used the oxygen must be passed through warm water in a humidifier or Woulfe's bottle. It is very important for the nurse to see that her patient breathes properly through the B.L.B. mask and keeps his mouth shut when the nasal type is used. If the patient empties the breathing bag at each inspiration, one or two of the inlet valves on the mask should be opened, for otherwise he will experience a sensation of suffocation.

Formerly no fluids were given by mouth during the induction period, but in later cases the practice was adopted of giving fluids from the beginning of treatment. In a large number of cases 1 per cent or 2 per cent glucose was added to the saline, but this has been discontinued. Drinks are no longer iced. At present drinks, each of 200 cubic centimetres, of cool 0.6 per cent saline solution, are given every fifteen minutes from the beginning of treatment as long as the patient tolerates them. If he complains of nausea the drinks are given less frequently or diluted to 0.3 per cent strength. If vomiting occurs the giving of fluids by mouth is discontinued and intravenous infusion of glucose saline may be necessary. In some cases administration of fluids by mouth may be gradually resumed later in 
treatment when the nausea has disappeared. A total of three to four litres of 0.6 per cent sodjum chloride solution is regarded as adequate for an eight-hour treatment. Fifty per cent glucose, given in 50 cubic centimetres or 100 cubic centimetres by intravenous injection, twice or three times during treatment, was formerly used as a routine in some earlier cases and in other cases as indicated, but this is no longer used. Normal saline with 5 per cent glucose is now used when required. The following are the indications for its use.

(1) Fall of systolic blood pressure below 100 millimetres of mercury.

(2) A poor quality pulse and a pulse giving successive readings over 160 beats per minute.

(3) Persistent vomiting during treatment.

(4) Total fluid intake of less than three litres.

The temperature of the patient was formerly maintained at $106 \cdot 6^{\circ} \mathrm{F}$. with an upper limit of $107 \cdot 0^{\circ} \mathrm{F}$. Experience has shown that with sulphonamide premedication equally good results are obtained at the $106.0^{\circ} \mathrm{F}$. level. This change was made on advice received from Dr. Kendell and has produced satisfactory results, with marked diminution in complications. The patient's temperature is now kept between $105 \cdot 8^{\circ} \mathrm{F}$. and $106 \cdot 2^{\circ} \mathrm{F}$. throughout treatment.

The eight-hour period of fever has been most generally used and recommended and has been adopted by us as a routine for this reason. Recently the use of iced drinks and the application of ice to the head and neck during treatment have been discontinued; and with this modification it has been found possible to maintain the patient's temperature with a cabinet temperature of from five to ten degrees less than that which was previously necessary. This point in technique was noted by one of us in a recent visit to various centres in the United States of America and has resulted in considerable improvement in the comfort and fitness of the patients.

Small doses of sedatives are used as a routine at certain stages of treatment at all fever therapy centres in America. The use of these drugs was discontinued by us for a time but has since been resumed. It has been our invariable experience that the careful use of small doses of selected sedatives has at all times resulted in improvement in the patient's mental and physical condition. The drug at present used by us is Alopon, which consists of the mixed hydrochlorides of the alkaloids contained in opium, and this has been given in doses of one-sixth of a grain either during or at the end of the induction period and repeated at three to four hour intervals if indicated. Neither morphine nor barbiturates have ever been used by us during fever therapy, and their administration is probably dangerous. It has been found that patients receiving fever treatment are disturbed by sudden noises and loud talking. Nurses and others present should wear rubber shoes and talk quietly. The patient should be shaded from. bright sunlight.

After-care and treatment.-The administration of oxygen, and particularly of oxygen and carbon dioxide mixture, by B.L.B. mask has for some time been a routine procedure following treatment and is considered to be of great importance. This administration is continued for at least one hour after the end of treatment and for further periods up to from three to four hours if indicated. This has undoubtedly much improved the general condition of the patient and has contributed to the diminution of such complications as anoxia and circulatory collapse. Patients are now kept in bed for one to three days after fever therapy, according to their general condition.

\section{Nursing standards}

It must be realized that the administration of high fever therapy involves many potential risks which will produce serious complications in the hands of any but the most experienced workers. The success of this type of treatment depends to a great extent on skilled and experienced nursing. Nurses should be young, of attractive personality and interested in their work. They require to be most carefully trained. The whole mental and physical condition of a patient can be 


\section{THE BRITISH JOURNAL OF VENEREAL DISEASES}

favourably influenced by. a nurse who is not only sympathetic but who is also a skilled technician.

\section{Indications for terminating treatment}

Some patients show signs which necessitate the termination of treatment. These are as follows.

(1) Uncontrolled rise in body temperature.

(2) Pulse rate which remains at over 160 beats per minute after the administration of intravenous fluids, or a pulse which is irregular or of poor volume and unimproved by similar means.

(3) Systolic blood pressure below 100 millimetres of mercury, which does not improve after administration of intravenous saline.

(4) Restlessness, disorientation and mental confusion which persist.

(5) Stupor which may be associated with incontinence of urine and faeces.

(6) Vomiting which persists after the giving of fluids by mouth has been stopped and after intravenous saline has been administered.

(7) Hysteria or lack of control which render the patient unmanageable.

(8) Tetany uncontrolled by inhalation of oxygen and carbon dioxide mixture or the intravenous injection of calcium gluconate.

(9) Facial pallor superimposed on cyanosis.

\section{Indications for fever treatmenit}

In treating cases of uncomplicated gonococcal and non-specific urethritis we have recommended and applied this treatment only for those in which routine treatment has been used and has failed. Practically all patients treated during the primary infection had received at least two courses of one or more sulphonamides and a course of urethral irrigations before hyperthermia was employed. The treatment has been used earlier in some cases of frequent relapse of infection and in a very few cases of soldiers occupying key positions urgently required by their units. In some of our cases, examples of which are given below, the patients had received prolonged treatment, numerous courses of various sulphonamides and other adjuvant measures having been applied.

\section{Standards of observation and tests for cure}

Most patients remained under immediate observation for a week after treatment by hyperthermia. The general experience was that on the morning after treatment had been given gonococci had disappeared from the discharge in gonorrhoeal cases and that in almost all cases the discharge was much diminished or absent. In the course of the next few days in the successful case all discharge disappeared and the first morning specimen of urine was free from pus. In a number of more resistant cases this cessation of the signs of infection was achieved with the aid of urethral irrigations for a few days. The patient was not discharged from hospital until there was complete absence of morning discharge and of leucocytes in the secretion obtained from within the meatus, and until the first morning specimen of urine was quite clear. For the next three weeks he was inspected weekly by his unit medical officer for early morning discharge and for evidence of infection in the first morning urine. If these tests were satisfactory he returned to normal diet including alcohol and was readmitted to hospital at the end of three months for microscopical tests of the early morning smear, the all-night urine and the prostatic secretion.

Urethroscopy and examination per rectum of prostate, seminal vesicles and Cowper's glands were also carried out. If all these tests were satisfactory he was discharged as cured. Culture of the vesiculo-prostatic secretions have not been possible under present conditions.

\section{Results of treatment}

The 418 cases under discussion fall into three main groups, A, B and C, details of which are given below. In the assessment which follows, the word, cure, is used to indicate apparent freedom from infection, and fitness for discharge from hospital and from the need for subsequent observation. 


\section{HYPERTHERMIA IN GONOCOCCAL AND NON-SPECIFIC URETHRITIS}

TABLE 1-GROUP A-319 CASES

Gonococci persisting in the Urethral Smear after Treatment by Sulphonamides

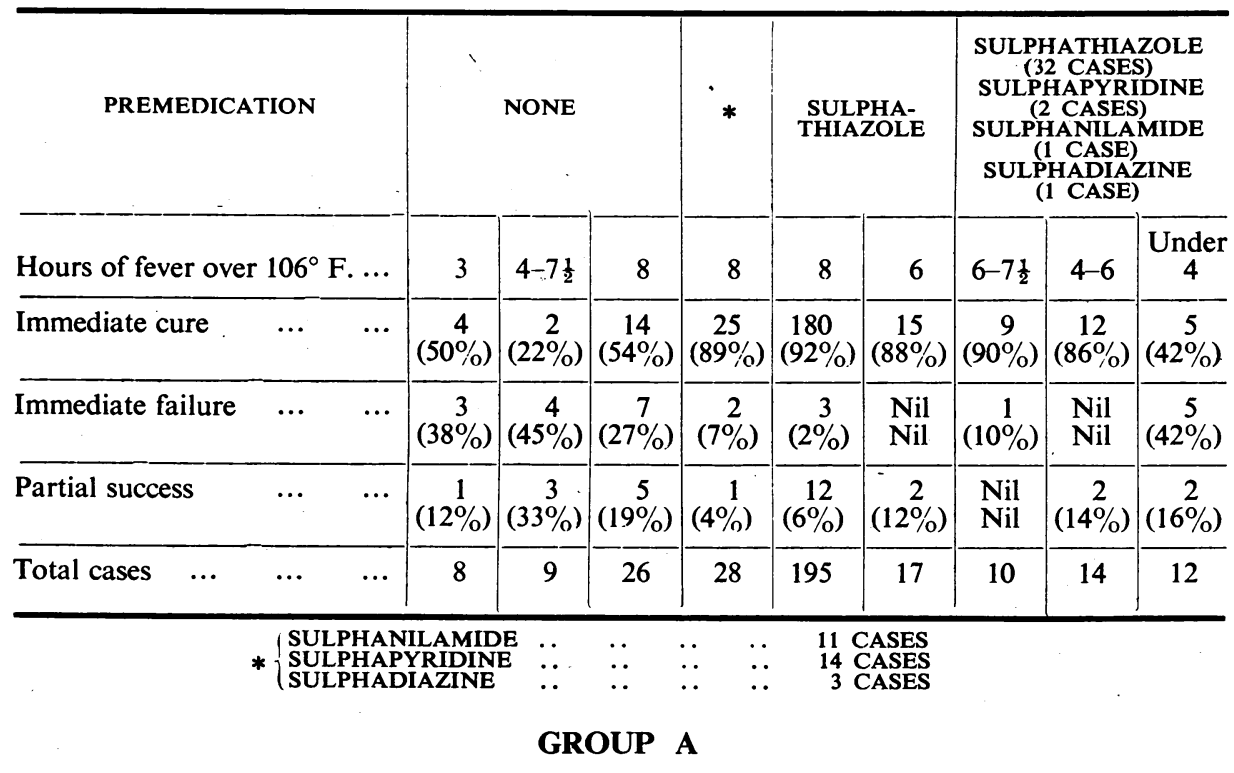

Consists of 285 cases of uncomplicated urethral gonorrhoea and 34 cases of gonorrhoea with local complications.

\section{(1) EIGHT-HOUR FEVER SESSIONS}

(a) No Premedication.-26 Cases.

(i) Immediate cure. -14 cases ( 54 per cent). Of these, 11 have passed tests of cure ; 1 has not been traced ; 2 are not due for tests.

(ii) Immediate failure.-Defined here and subsequently as persistence of the gonococcus in the urethral discharge after fever. 7 cases ( 27 per cent). Of these, 4 were cured after further sulphonamide treatment $(2$ have passed final tests of cure and 2 have not been traced) ; 1 was cured after local treatment and has not been traced ; 2 were cured after a second session of eight hours' fever given with sulphathiazole (1 passed final tests of cure, 1 relapsed with gonococcal infection).

(iii) Partial success.-Defined as disappearance of the gonococcus from the urethral smear but the requirement of further sulphonamide with or without fever to achieve cure. 5 cases (19 per cent). All 5 passed tests of cure.

(b) Premedication with Sulphanilamide (11 cases), with Sulphapyridine (14 cases) and with Sulphadiazine ( 3 cases). - Total, 28 cases.

(i) Immediate cure. -25 cases ( 89 per cent). Of these, 18 have passed tests of cure; 4 have not been traced ; 2 are not yet due for tests of cure ; 1 relapsed with nonspecific urethritis.

(ii) Immediate failure.-2 cases ( 7 per cent). Both these were cured after further fever for 8 hours with no premedication and passed final tests of cure.

(iii) Partial success. -1 case (4 per cent). Final tests are not due in this case.

(c) Premedication with Sulphathiazole.-195 cases.

(i) Immediate cure. -180 cases ( 92 per cent). Of these, 62 have passed tests of cure ; - 53 have not been traced ; 57 are not yet due for tests of cure ; 1 relapsed with non-specific urethritis ; 3 relapsed with gonococcal infection ; 4 are possible relapses but all admit further exposure to infection.

(ii) Immediate failure. -3 cases ( 2 per cent). Of these, 1 was cured after further sulphonamide ; 1 was cured after a further 8-hour session of fever with sulphathiazole ; 1 was still a failure after a second fever session, but was cured with further sulphadiazine.

(iii) Partial success. -12 cases (6 per cent). Of these, 2 have passed tests of cure ; 4 have not been traced ; 5 are not yet due for tests of cure. In 1 case, despite a second fever session, urinary infection persisted ; the gonococcus was not seen after the first treatment. 


\section{THE BRITISH JOURNAL OF VENEREAL DISEASES}

\section{(2) SIX-HOUR FEVER SESSIONS}

Premedication with Sulphathiazole (16 cases) and Sulphadiazine (1 case, not shown on Chart).Total, 17 cases.

(i) Immediate cure. -15 cases (88 per cent). Of these, 5 have passed tests of cure ; 8 have not been traced ; 2 are not yet due for tests.

(ii) Immediate failure.-Nil.

(iii) Partial success. -2 cases (12 per cent). Of these, 1 was cured by further sulphonamide and was later admitted-with presumed reinfection; 1 was cured after 8 hours of fever with sulphathiazole and has not been traced.

\section{(3) THREE-HOUR FEVER SESSIONS}

No Premedication. -8 cases.

(i) Immediate cure. -4 cases (50 per cent). Of these, 3 have passed tests of cure ;' 1 relapsed with gonorrhoeal infection.

(ii) Immediate failure. -3 cases (38 per cent). Of these 1 was cured after further sulphona-mide ; 1 was cured after 8 hours of fever with no premedication; 1 was cured after two more 3-hour sessions without premedication. All 3 have passed tests of cure.

(iii) Partial success. -1 case (12 per cent). This man has not been traced.

(4) TREATMENT STOPPED BEFORE THE AIM OF 8 HOURS WAS REALIZED (45 CASES)

(a) No Premedication.-9 cases. Duration of fever therapy, 4 to $7 \frac{1}{2}$ hours.

(i) Immediate cure. -2 cases (22 per cent).

(ii) Intmediate failure. -4 cases ( 45 per cent). All were cured by further treatment with a sulphonamide ; 1 is known to have relapsed and 3 to have passed tests of cure.

(iii) Partial success.-3 cases (33 per cent). All passed tests of cure.

(b) Premedication with Sulphathiazole ( 32 cases), with Sulphapyridine (2 cases), with Sulphanil ${ }^{-}$ amide (1 case) and with Sulphadiazine (1 case).-Total, 36 cases. Duration of fever therapy, 6 to $7 \frac{1}{2}$ hours, 10 cases.

(i) Immediate cure. -9 cases (90 per cent).

(ii) Immediate failure. -1 case (10 per cent). This patient was cured later after 8 hours of fever with sulphathiazole.

Duration of fever therapy. -4 to 6 hours, 14 cases.

(i) Immediate cure. -12 cases (86 per cent).

(ii) Partial success. -2 cases (14 per cent). One of these is known to have relapsed with a gonorrhoeal infection.

Duration of fever therapy.--Under 4 hours, 12 cases.

(i) Immediate cure. -5 cases (42 per cent).

(ii) Immediate failure. -5 cases ( 42 per cent). Of these, 1 was cured by 8 hours' fever and sulphathiazole ; 1 was cured by 5 hours' fever and sulphathiazole; 2 were apparently cured by further sulphonamide and 1 by local treatment : all these 3 soon relapsed.

(iii) Partial success.-2 cases (16 per cent). Of these, 1 relapsed with gonorrhoeal infection; 1 has not been traced.

TABLE 2-GROUP B-23 CASES

Originally treated for Gonorrhoea with a Persistent Urethral Discharge or Signs of Infection in the Urine

\begin{tabular}{|c|c|c|c|c|c|c|}
\hline \multicolumn{4}{|c|}{ PREMEDICATION } & \multicolumn{2}{|c|}{ NONE } & \multirow{2}{*}{ 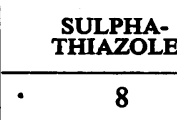 } \\
\hline Hours of fever & over $106^{\circ} \mathrm{F}$ & $\ldots$ & $\ldots$ & .6 & 8 & \\
\hline Immediate cure & $\ldots$ & $\cdots$ & $\cdots$ & $\begin{array}{c}2 \\
(67 \%)\end{array}$ & $\begin{array}{c}2 \\
(33 \%)\end{array}$ & $\begin{array}{c}11 \\
(79 \%)\end{array}$ \\
\hline Partial success & $\ldots \cdot \ldots$ & $\therefore$ & $\cdots$ & $\therefore \quad \begin{array}{c}1 \\
(33 \%)\end{array}$ & $\begin{array}{c}3 \\
(50 \%)\end{array}$ & $(21 \%)$ \\
\hline$\overline{\text { Died }}$ & $\cdots$ & $\cdots$ & $\cdots$ & - & 1 & - \\
\hline Total cases & $\cdots \quad \cdots$ & $\cdots$ & $\cdots$ & 3 & 6 & 14 \\
\hline
\end{tabular}




\section{HYPERTHERMIA IN GONOCOCCAL AND NON-SPECIFIC URETHRITIS}

\section{GROUP B}

Consists of those originally treated for gonorrhoea with a persistent urethral discharge in which gonococci could not be found, or with persistent signs of infection in the urine. Total cases, 23.

(1) EIGHT-HOUR FEVER SESSIONS

(a) No Premedication. -6 cases.

(i) Immediate cure. -2 cases ( 33 per cent).

(ii) Partial success. -3 cases ( 50 per cent).

(iii) Died.-1 case.

(b) Premedication with Sulphathiazole.-14 cases.

(i) Immediate cure.-11 cases (79 per cent). All have passed tests of cure.

(ii) Partial success. -3 cases (21 per cent). Of these, 2 cases were cured by a further 8-hour session of fever with sulphonamide premedication and passed tests of cure ; 1 case was cured by further sulphonamide only.

(2) SIX-HOUR FEVER SESSIONS

No Premedication. -3 cases.

(i) Immediate cure. -2 cases (67 per cent).

(ii) Partial success. -1 case (33 per cent).

TABLE 3-GROUP C-76 CASES

Non-specific Urethritis

\begin{tabular}{|c|c|c|c|c|c|c|c|c|}
\hline \multicolumn{5}{|c|}{ PREMEDICATION } & NONE & * & $\begin{array}{l}\text { SULPHATHIA- } \\
\text { ZOLE IN ALL } \\
\text { BUT ONE }\end{array}$ & VARIOUS \\
\hline \multicolumn{3}{|c|}{ Hours of fever over $106^{\circ} \mathrm{F}$. } & ... & $\ldots$ & 8 & 8 & 6 & Under 6 \\
\hline Immediate cure & & $\cdots$ & $\cdots$ & $\cdots$ & $\begin{array}{c}6 \\
(46 \%)\end{array}$ & $\begin{array}{c}30 \\
(64 \%)\end{array}$ & $\begin{array}{c}4 \\
(50 \%)\end{array}$ & $\begin{array}{c}2 \\
(25 \%)\end{array}$ \\
\hline Failures ... & $\cdots$ & $\ldots$ & $\ldots$ & $\ldots$ & - & $\begin{array}{c}5 \\
(11 \%)\end{array}$ & - & - \\
\hline Partial success & $\cdots$ & $\cdots$ & $\ldots$ & $\cdots$ & $\begin{array}{c}7 \\
(54 \%)\end{array}$ & $\begin{array}{c}12 \\
(25 \%)\end{array}$ & $\begin{array}{c}4 \\
(50 \%)\end{array}$ & $\begin{array}{c}6 \\
(75 \%)\end{array}$ \\
\hline \multirow[t]{2}{*}{ Total cases } & $\ldots$ & $\ldots$ & $\ldots$ & $\ldots$ & 13 & 47 & 8 & 8 \\
\hline & \multicolumn{4}{|c|}{$* \begin{array}{l}\text { SULPHATHIAZOLE } \\
\text { SULPHAPYRIDINE } \\
\text { SULPHANILAMIDE }\end{array}$} & $\begin{array}{l}. . \\
\because .\end{array}$ & \multicolumn{2}{|c|}{$\begin{array}{l}37 \text { CASES } \\
5 \text { CASES } \\
5 \text { CASES }\end{array}$} & \\
\hline
\end{tabular}

Consists of cases of non-specific urethritis with or without a history of gonorrhoea. Total cases, 76.

The following classification is given to indicate that all types of resistant cases were treated without special selection.

- Types of Cases
$\begin{array}{llllll}\text { (a) Previous gonorrhoea } & \ldots & \ldots & \ldots & \ldots & 18\end{array}$

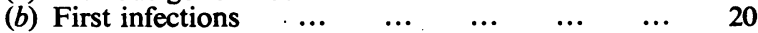

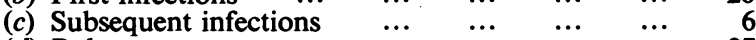
$\begin{array}{llllllll}\text { (d) Relapses } & \ldots & \ldots & \ldots & \ldots & \ldots & \ldots & 27\end{array}$

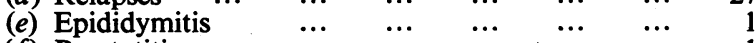

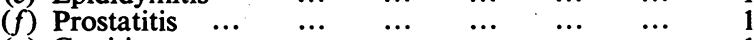
$\begin{array}{llllllll}\text { (g) Cystitis } & \ldots & \ldots & \ldots & \ldots & \ldots & \ldots & 1\end{array}$
(h) Diverticulum of bladder $\begin{array}{lllll}\ldots & \ldots & \ldots & \ldots & 1\end{array}$
(i) Old-standing stricture and urethritis $\quad \ldots \quad \ldots$

(1) EIGHT-HOUR FEVER SESSIONS

(a) No Premedication.-13 cases.

(i) Immediate cure. -6 cases ( 48 per cent). Of these, 5 have passed tests of cure ; 1 has not been traced.

(ii) Partial success. -7 cases ( 54 per cent). All were cured with further sulphonamide, with additional fever in 1 case. Of these, 4 have passed tests of cure ; 2 have not been traced ; 1 is still receiving treatment for an old-standing stricture. 


\section{THE BRITTSH JOURNAL OF VENEREAL DISEASES}

(b) Premedication with Sulphathiazole (37 cases), with Sulphanilamide (5 cases) and with Sulphapyridine (5 cases).- - Total, 47 cases.

(i) Immediate cure, -30 cases (64 per cent). Of these, 17 have passed tests of cure ; 6 háve relapsed; 6 have not been traced; 1 is not yet due for tests.

(ii) Partial success.-12 cases (25 per cent). Of these, 3 required further fever therapy, were cured and passed tests of cure ; 9 required further sulphonamide to achieve cure ; 1 relapsed; 6 have not been traced; 2 have passed tests of cure.

(iii) Failure. -5 cases (11 per cent).

\section{(2) SIX-HOUR FEVER SESSIONS}

Premedication with Sulphathiazole in all but 1 case. -8 cases.

(i) Immediate cure. -4 cases (50 per cent). All these have passed tests of cure.

(ii) Partial success. -4 cases (50 per cent). Cured with further sulphonamide, plus fever in 1 case. One of these has relapsed.

(3) LESS THAN SIX-HOUR FEVER SESSIONS. -8 cases.

(i) Immediate cure. -2 cases ( 25 per cent). One of these relapsed.

(ii) Partial success. -6 cases ( 75 per cent). Cured with further sulphonamide, plus fever in 1 case.

\section{Complications of treatment}

Anoxia.- In the course of treatment a number of patients showed in varying degree symptoms and signs which have been attributed to the effects of lack of oxygen upon certain tissues. The manifestations were as follows. (1) Cyanosis of varying degree. (2) Drowsiness deepening in some cases to stupor and coma. (3) Marked rapidity and shallowness of respiration, the rate per minute rising to as much as 60. (4) Restlessness, delirium and violence. (5) Peripheral circulatory collapse late in treatment or after the termination of treatment. (6) The occurrence of subclinical jaundice rising to the clinical level in some cases especially when some degree of circulatory collapse has occurred.

Wallace took the view that these changes were produced entirely by prolonged lack of sufficient oxygen in certain tissues, especially the brain and liver, due either to increased metabolic requirements in prolonged high fever and relative anoxaemia or to some histo-toxic effect of the fever whereby tissues were damaged and unable to effect interchange of oxygen available in the blood stream. Others have recognized the desirability of continuous oxygen administration and for some years this has been recommended and practised by Simpson, Kendell and Rose. The experimental work of Cullen, Weir and Cook (1942), although applied in relatively few cases, illustrates strikingly the beneficial effects of oxygen when administered during treatment by means of the oro-pharyngeal catheter. In their patients there was an increase in the alveolar concentration of oxygen and an increased saturation of the blood, with consequent increase of oxygen tension in spite of an elevated hydrogen-ion concentration. Clinically the pulse rates were slowed, and restlessness, mental confusion and excitement were less frequent and less marked ; fewer sedatives were required and fewer treatments had to be discontinued. Our experience is that the continuous administration of oxygen during treatment has been of yalue in diminishing the severity of these effects, but has never prevented their development in some degree in susceptible patients. Much more effective in diminishing the rate of incidence and the severity of this complication has been restriction of the patient's temperature to $106^{\circ} \mathrm{F}$. and prevention of rises to $106.6^{\circ} \mathrm{F}$. or $106.7^{\circ} \mathrm{F}$., which were a routine in the earlier technique. The significance of this dangerous but obscure complication was discussed by one of us in a recent visit to the Laboratory of Metabolic Investigation at the Mayo Clinic where Dr. Boothby and his associates were engaged on research in aviation medicine. Dr. Boothby was absent but the problem of anoxia in high fever therapy was discussed with Dr. C. F. Code (1943), to whom a full description of the complications we had seen and of the investigations which had been carried out were given. Dr. Code expressed his opinion that the clinical picture described was not that of simple anoxia but one in which anoxia seemed to be only a compli- 


\section{HYPERTHERMIA IN GONOCOCCAL AND NON-SPECIFIC URETHRITIS}

cation of the condition. With true anoxia such as he had seen so often in his experimental work in aviation, cerebral involvement would have been a much more marked and lasting feature. He suggested that the patients described were suffering from the toxic effects of tissue destruction perhaps due to fever alone, or to some other undiscovered predisposing factor. For example, the administration of an arsenical compound intravenously to a syphilitic patient at high fever could be such a factor. Any additional toxic agent administered might tip the scale in such a rigorous treatment. After further consideration of this subject Dr. Code wrote to us about the matter which is of such importance that the relevant part of his letter is quoted verbatim below.

I have been giving your problem a good deal of thought. The more I think it over in my mind, the more difficult it seems to make a clear-cut distinction between anoxia and tissue damage. Anoxia will cause tissue damage and will give late symptoms resembling those of tissue damage from other causes. Tissue damage in the body can give symptoms resembling those of anoxia.

At ordinary body temperatures when anoxia causes tissue damage, it damages the tissues most sensitive to oxygen lack. These are the cells of the higher brain centres. On the basis of the evidence available I do not believe you could have such a severe reaction in your patients without there being clearer signs of cerebral damage had the reaction been due to anoxia alone. In anoxia it is the brain which is damaged. Your people should have shown severe prolonged coma and some more or less permanent neurological changes with the degree of hyperpyrexia you encountered, had it been on a simple anoxia basis. Your patients, instead of showing clear-cut signs of cerebral damage, showed clear-cut signs of liver damage. Simple anoxia at ordinary body temperature would have picked out the brains of your patients and left you with some comatosed patients who, if they had lived, would have at least had ataxia and some diminution in intellectual capacity.

There is only one loophole, as I see it, in this argument. It is : Does anoxia at high body temperature produce a different symptom complex from anoxia at normal body temperatures? This question has not been answered.

You most certainly had anoxia in your patients, but in the light of existing evidence it would seem to be the result rather than the cause of the syndrome. When the blood pressure falls as a result of cerebral anoxia, the patient either dies or recovery of the blood pressure is prompt. In animals the period of blood pressure fall usually lasts for only eight or ten minutes. The prolonged shock which your patients developed suggests some other factor. There is reason to suggest that had the medullary centres been sufficiently damaged to produce the degree of shock your patients showed, they would not have survived. They could hardly have survived without other signs of cerebral and cerebellar dysfunction. The cerebellar and cortical cells are much more sensitive to anoxia than the centres of the medulla.

Pending some further clarification of the cause of this complication it is at any rate a matter of experience that the effects can be prevented or minimized in three ways as follows: (1) by restricting the temperature level to $106^{\circ} \mathrm{F}$. throughout treatment ; (2) by the continuous administration of oxygen or oxygen and carbon dioxide mixture ( 5 to 7 per cent) to the patient throughout treatment ; (3) by the administration of oxygen and carbon dioxide to the patient during the period of recovery from fever for as long as his condition seems to require it.

Liver damage.-In this series forty-one cases of clinical jaundice occurred; the condition was usually mild and transient. Subclinical jaundice was common. A rise above 0.6 van den Bergh units was found in 75 per cent of forty patients whose serum bilirubin was examined before fever and for three days afterwards, the maximal rise in most cases being found on the first day after treatment. The return to normal levels was rapid and recovery was complete in every case. Estimation of the serum. bilirubin before a second treatment is a routine in this department and has always shown readings within normal limits. The intravenous hippuric acid test has been carried out in forty cases on the day previous to and on the third day after treatment. In twenty-eight of these there was normal liver function as judged by this test. There was no significant difference in the incidence of jaundice in cases treated with or without sulphonamide premedication. There was a higher incidence of jaundice when the body temperature was maintained at the $106.6^{\circ} \mathrm{F}$. level and particularly so if sudden rises of temperature above this 


\section{THE BRITISH JOURNAL OF VENEREAL DISEASES}

level took place. A patient with circulatory collapse would almost certainly develop jaundice.

In America where this type of jaundice is a rarity, except when fever is combined with arseno-therapy, it was suggested in the early days of fever therapy that deficiency of sodium chloride was the cause: With this idea in mind sodium chloride was given for two days before treatment. Glucose, the text-book protector of assaulted livers, was also given over this period and added to the sodium chloride given during treatment. These steps had no effect on the incidence of jaundice nor on the well-being of the patients; indeed our experience was that glucose given during treatment might give rise to vomiting.

Recently the possibility of a dietetic deficiency as an aetiological factor has been considered. Miller and Whipple $(1940 ; 1942)$ and Miller, Ross and Whipple (1940) showed that sulphur-containing proteins and not carbohydrates are essentially necessary to protect the livers of dogs against damage by chloroform. As described, our routine before treatment has been adjusted with this idea in view ; milk, eggs, cheese and cysteine ester are given during the two days before fever

- therapy. Subclinical and occasional clinical jaundice still occur but there is no doubt that the general condition of the patients at the end of treatment and on the following days has been better since this regime was instituted. The cause of the jaundice is obscure, but we would suggest that it may be due to the direct effect of heat on a liver deficient in the sulphydryl radical under the stress of oxygen lack and having to deal with the sudden increase of its own and the body metabolites.

Kidney damage. - There has been no evidence of kidney damage resulting from high fever therapy in any of our patients and as far as we are aware the only known cases of toxic nephritis have occurred in patients who have received large doses of arsenicals in conjunction with fever for the intensive treatment of syphilis.

Tetany.-A number of obscure symptoms and signs have been attributed to this cause by various workers in this field. As far as our evidence goes two types of this complication can be recognized and both of them occur only occasionally.

(1) Manifestations of tetany occur during the induction period and are believed to be caused by hyperventilation resulting in a fall of carbon dioxide tension in the circulating blood with subsequent alkalosis. Muscular tremors and cramps may occur and in more severe cases, carpo-pedal spasms. The inhalation of oxygen combined with 5 to 7 per cent of carbon dioxide during the induction period is a good method of prophylaxis. The condition is also usually relieved by intravenous injection of one gramme of calcium gluconate in watery solution. This dose may have to be repeated if relief is not prompt and satisfactory: According to Kendell (1943) the complication is not prevented by giving calcium gluconate by mouth between treatments.

(2) Hypochloraemic tetany occurs late in treatment or within the first few hours after treatment and is due to failure to replace sufficient of the sodium chloride lost in the sweat. It is characterized by muscular cramps which usually involve the abdominal muscles and is relieved by suitable administration of sodium chloride solution by mouth or intravenously.

Skin burns.- These have been eliminated for practical purposes with up-to-date apparatus. They have occurred in our patients treated by the old type of cabinet but have become quite rare with improving technique.

Herpes febrilis.- This is a common sequel to treatment and has occurred in ninety-three of these cases. The eruption usually affects the skin round the mouth and often the mucous membrane of tongue and cheeks; sometimes it affects the skin round the nose and ears. In one case, not in this series, the distribution was perianal. We know of no means of prevention but most lesions clear up in a few days with local treatment. Dendritic ulcers have occurred on the cornea in three of our cases, two of them in this series.

Incontinence of urine and faeces.-This occurs occasionally after treatment usually in patients who have shown drowsiness or delirium. This complication possibly belongs to the group described under the heading, Anoxia. 
Backache.-A few patients complain of severe backache after treatment. The reason for this is not clear but it may be a hypochloraemic phenomenon affecting the lumbar muscles. Occasionally it is relieved when the patient passes urine.

Facial palsy.-Two of our patients developed right-sided facial palsy during the few days following treatment. Whether this was in any way connected with the treatment we were unable to say. In one case motor power was restored very quickly but in the other the condition was very resistant.

Tachycardia.-The importance of this sign, which presumably indicates myocardial overstress, has been mentioned in relation to the signs and symptoms which demand cessation of treatment. It is an interesting point that this complication, which was previously uncommon and usually remedied without difficulty, has occurred more frequently and often with persistence in recent months. Most of the patients affected have had very large doses of various sulphonamides before they were transferred to us. In this group the doses received had varied from 300 to 900 grammes of a sulphonamide. In some cases treatment with a sulphonamide had been continued intermittently for as long as eight months.

Secondary reactions due to intravenous infusions.-At one stage our treatment was complicated by secondary reactions due to intravenous infusions. The effect in most cases was to produce a rigor, although the patient's temperature was already $106 \cdot 0^{\circ} \mathrm{F}$., followed by a further rise of temperature which was difficult to control and subsequently by a variable degree of circulatory collapse. - A number of these patients developed jaundice. It is, of course, essential at all times to ensure the freedom of fluids for intravenous infusion from pyrogenic substances and to keep close watch on methods of sterilization, the possibility of reactions due to the water in which the syringes and needles are boiled, and also of reactions due to new and insufficiently treated rubber tubing. In our earlier work intravenous infusions were often given very rapidly but no evidence of reactions due to this cause was seen.

Fatalities.-Two of our earlier patients died as the result of treatment but one only is included in this series. The clinical picture was that of heatstroke.

TABLE 4

Summary of Results in Gonorrhoea and Non-Specific Urethritis

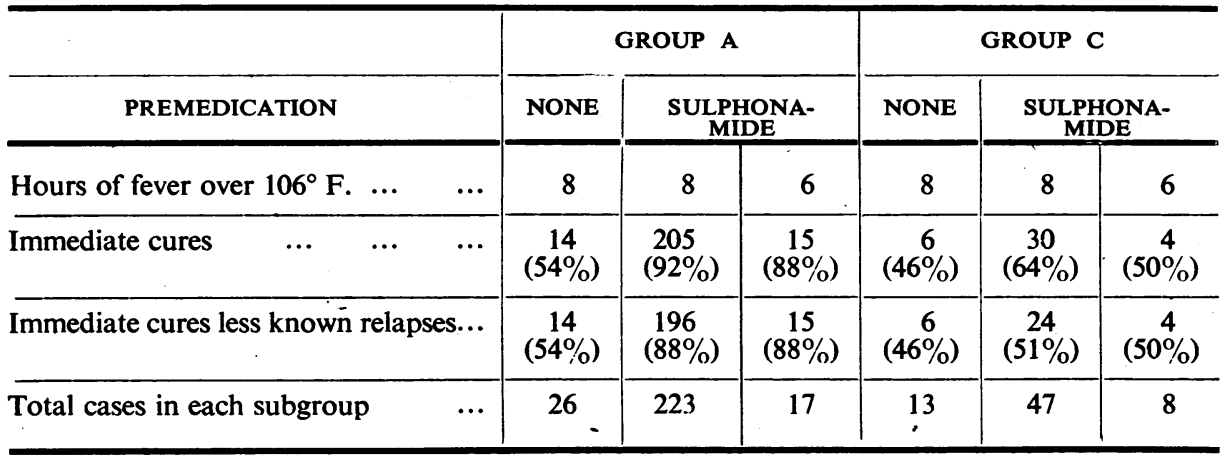

\section{Summary and discussion}

Indications and technique for hyperthermia with the Kettering Hypertherm in the treatment of cases of resistant gonococcal and non-specific urethritis have been discussed. The results obtained with sessions of high fever at $106^{\circ} \mathrm{F}$. with and without premedication with various sulphonamides have been tabulated. For the sake of comparison the results obtained with eight- and six-hour sessions of fever with and without sulphonamide premedication in cases of gonorrhoea and non-specific urethritis are summarized in Table 4. This shows that in cases of resistant gonococcal urethritis high fever with sulphonamide premedication is considerably superior to high fever alone. The figures also suggest that 


\section{THE BRITISH JOURNAL OF VENEREAL DISEASES}

with sulphonamide premedication there is little to choose between the results obtained with sessions of eight and six hours. We are, however, reluctant to draw such a conclusion on the present evidence owing to the small number of cases in the six-hour group and the fact that all our most difficult cases were included in the eight-hour group. The group of post-gonococcal infections is too small for comparison. The group of infections which appeared to be truly non-specific was also small, but as far as the evidence goes it shows that this type of treatment is less effective in these cases and that the advantages of premedication with sulphonamides are less marked. The complications of this treatment and means for their prevention have been discussed.

\section{Conclusions}

(1) High fever mechanically produced is the treatment of choice for resistant gonococcal urethritis.

(2) It is much more effective when combined with sulphonamide premedication.

(3) The duration of fever required varied with the individual case but sessions of six and eight hours produced a high proportion of successes.

(4) Cases in which hyperthermia was not followed by immediate cure frequently responded to measures which had previously failed.

(5) This treatment was less effective but still of value in the treatment of resistant cases of non-specific urethritis.

(6) The potential dangers of this treatment can be reduced to a minimum by careful and skilful technique.

Our thanks are due to Brig. T. E. Osmond, A.M.S., for constant encouragement and support and to Col. G. P. Kidd, M.C., A.M.S., for permission to publish these results. Acknowledgments are also due to Professor R. A. Peters and Dr. R. S. Thompson, for helpful advice and for making available supplies of cysteine ester.

\section{REFERENCES}

Batchelor, R. C. L., Thomson, G. M., and Huggan, J. L. (1942) Edinb. med. J., 49, 584.

Belt, E., and Folkenberg, A. W. (1940) Arch. phys. Ther., 21, 203.

Code, C. F. (1943) Personal communication.

Cullen, S. C., Weir, E. F., and Cook, Evelyn (1942) Anesthesiologv, 3, 123.

Ferguson, C., Buchholtz, M., Gersten, S., and Cutler, J. (1942) Vener. Dis. Inform., 23, 377.

Kendell, H. W. (1943) Personal communication.

Miller, L. L., and Whipple, G. H. (1940) Amer. J. med. Sci., 199, 204.

- - (1942) J. exp. Med., 76, 421.

- Ross, J. F., and Whipple, G. H. (1940) Amer. J. med. Sci., $200,739$.

Rose, D. L., Kendell, H. W., and Simpson, W.M. (1941) War Med., 1, 470.

Simpson, W. M., Rose, D. L., and Kendell, H.W . (1941) Brit. J. vener. Dis., 17, 185.

\section{Treatment of fusospirillary balanitis}

Local treatment with a preparation of stovarsol containing merfenil, 1 in 100,000 , is advocated for balanitis circinata by $G$. M. Thomson in cases where fusospirillary infection is found on bacteriological investigation. The use of this preparation, following local hygiene with saline, in thirty-eight cases gave'excellent results in all, healing having been attained in an average of 3.5 days.-British Medical Journal, 16th October, 1943.

\section{Incidence of syphilis among juvenile mental defectives}

The incidence of syphilis among juvenile mental defectives of low grade was investigated by $\mathbf{J}$. Lloyd in hospital inmates during the years 1938-42. In a total of 512 children whose average age was 5.5 years he found the blood Wassermann reaction to be positive in four cases only $(0.78$ per cent). He points out that among older mental defectives a positive blood Wassermann reaction is much commoner than in this group and infers that syphilis appears to be decreasing among parents of mental defectives, although a possible alternative explanation of the results is that an increasing proportion of mothers may have been receiving treatment.-British Medical Journal, 2nd October, 1943. 